\title{
Thallium isotope cycling in a manganese-rich brackish meromictic pond
}

\author{
CHADLIN M OSTRANDER ${ }^{1}$, SUNE GRØNLUND \\ NIELSEN $^{1}$, HAYLEY J GADOL ${ }^{2}$, TRISTAN J HORNER ${ }^{1}$ \\ AND COLLEEN M HANSEL ${ }^{1}$
}

${ }^{1}$ Woods Hole Oceanographic Institution

${ }^{2}$ Massachusetts Institute of Technology

Presenting Author: costrander@whoi.edu

There has been a recent acceleration in the use of thallium (Tl) isotopes to track changes in past ocean oxygenation. Critically, $\mathrm{Tl}$ isotopes are not directly sensitive to $\mathrm{O}_{2}$, but instead sensitive to manganese $(\mathrm{Mn})$ oxide minerals that can form in the presence of $\mathrm{O}_{2}$. This utility therefore demands a strong understanding of how $\mathrm{Tl}$ isotopes are cycled in the presence of Mn oxides.

In this presentation, we will discuss our recent investigation of T1 isotope cycling in Siders Pond (Massachusetts, USA). Siders Pond is a meromictic kettle hole ( $\sim 15$ meters deep) located inland of the Vineyard Sound on Cape Cod. The pond is salinityand redox-stratified, with $\mathrm{O}_{2}$-bearing freshwaters overlying anoxic to euxinic, dense saltier waters. Formation of Mn oxides in surface waters of the pond is at times extremely efficient and highly dynamic (i.e., fluctuating over weeks to months), making this an ideal field site to test the linkages between Mn oxide cycling and $\mathrm{Tl}$ isotope variations.

We find highly variable $\mathrm{Tl}$ isotope compositions $\left(\varepsilon^{205} \mathrm{Tl}\right)$ in waters and particles collected from Siders Pond during the 2020 field season - variations that are probably linked to dynamic Mn cycling. Particles collected in surface waters in September and November were always isotopically heavier than coeval waters, but especially heavier when $\mathrm{Mn}$ oxide formation peaked in September (up to 4.5 epsilon units heavier). Manganese oxides are known to preferentially sorb the heavier-mass $\mathrm{Tl}$ isotope. Moreover, especially heavy $\varepsilon^{205} \mathrm{Tl}$ in surface waters in August (up to $\varepsilon^{205} \mathrm{Tl}=-0.1$ ) could have been a consequence of Mn oxide dissolution. Particulate Mn oxide concentrations on this day were low, and any dissolution would have led to the release of isotopically heavy $\mathrm{Tl}$.

These hypotheses, and others, will be tested during the upcoming 2021 field season. We will also generate $\varepsilon^{205} \mathrm{Tl}$ for pond sediments to see what imprints, if any, these dynamic water column Mn-Tl interactions might leave behind in the sedimentary record. Any imprints that are recorded must be taken into consideration when using $\mathrm{Tl}$ isotopes to track past ocean oxygenation. 